\title{
Gain Enhancement of Low-Profile, Electrically Small Capacitive Feed Antennas Using Stacked Meander Lines
}

\author{
Kazuki Ide, Satoshi Ijiguchi, and Takeshi Fukusako \\ Department of Computer Science and Electrical Engineering, Kumamoto University, 2-39-1, Kurokami, Kumamoto 860-8555, Japan \\ Correspondence should be addressed to Takeshi Fukusako, fukusako@cs.kumamoto-u.ac.jp
}

Received 25 February 2010; Accepted 5 August 2010

Academic Editor: Miguel Ferrando

Copyright () 2010 Kazuki Ide et al. This is an open access article distributed under the Creative Commons Attribution License, which permits unrestricted use, distribution, and reproduction in any medium, provided the original work is properly cited.

The present paper describes the gain enhancement of a small and low-profile linear antenna with capacitive feed (C-feed) using three metallic layers. The antenna has very small leakage current on the outer conductor of the coaxial cable and can easily control the imaginary part of the input impedance. The gain of the stacked three-layer meander line antenna, with the meander line in the middle layer being opposite to that of the other two layers, has increased by around $7 \mathrm{~dB}$ compared to the single layered Cfeed antenna. The antenna gain is discussed based on simulated and measured results, which demonstrates that the antenna has successfully achieved the acceptable impedance and sufficient gain for mobile terminals and RFID tags.

\section{Introduction}

Small [1-3], low-profile antennas [4-6] with back reflectors have been widely studied in recent years. The antenna which is close to the back conductor can reduce the electrical effects from the backing material when the antenna is installed on IC chips, human body, or any metallic or lossy materials. Using a folded line such as meander lines [7-9] and incorporating capacitances $[10,11]$ are effective ways to make electrically small antennas to operate at the serial resonance frequency. A small, low-profile antenna having an electrically small and low-profile structure that uses a capacitive coupling with a back conductor and that can be operated at the serial frequency has been presented in [12]. However, the coupling terminal with small area easily generates leakage current on the feeding coaxial cable unless a ferrite choke on the cable is used. The leakage current existing on the outer surface of a coaxial cable causes drastic changes in antenna characteristics $[13,14]$ when the feed is unbalanced. Moreover, typical electrically small and low-profile antennas have disadvantages of low radiation efficiency [15], and it is difficult to attain impedance matching characteristics [16]. The problems of the leakage current and the impedance matching can be improved by a capacitive feed (C-feed) technique in [17].
This paper pr oposes the techniques to enhance the antenna gain of the C-feed mender line antenna (CFMA) shown in [17]. Additional meander line layers are stacked on the CFMA to enhance the antenna gain. The gain of the two-layered CFMA (2L-CFMA) with opposite meander lines has increased by around $6 \mathrm{~dB}$ compared to the CFMA. Furthermore, a three-layered CFMA (3L-CFMA) with a reversed meander line to that of the adjacent layers incorporated at the feed plate can enhance the gain by around $7 \mathrm{~dB}$ as compared to the CFMA.

\section{Low-Profile, Electrically Small Meander Antenna Using a Capacitive Feed Structure}

A design of electrically small and low-profile linear antenna with a reflector has been reported in [12, 17]. The antenna yields capacitive impedance at low frequency and approximates the parallel resonant frequency as the serial resonant frequency. Figures $1(\mathrm{a})$ and $1(\mathrm{~b})$ show the top and bird's-eye view of dismantled CFMA. The antenna has a height (the distance between the antenna and the back conductor $)$ of $2 \mathrm{~mm}\left(0.008 \lambda_{0}<0.25 \lambda_{0}, \lambda_{0}\right.$ : wavelength at resonance frequency) and uses RT/Duroid 5880 substrate with a permittivity $\left(\varepsilon_{r}\right)$ of 2.2 and dielectric loss $(\tan \delta)$ 


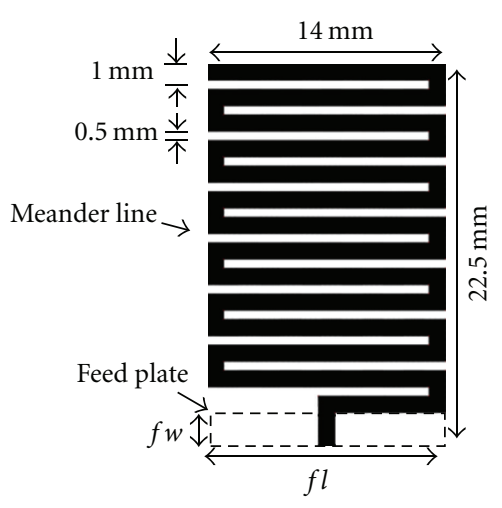

(a) Top view

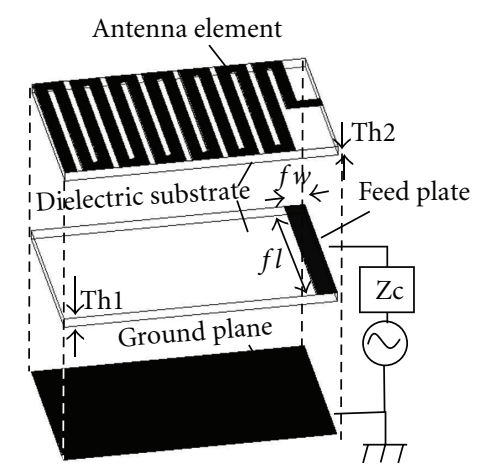

(b) Dismantled structure

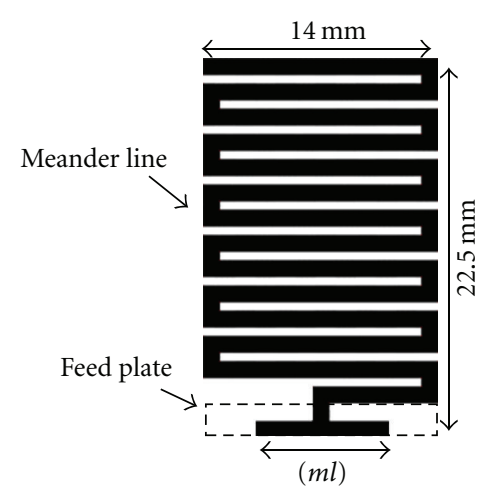

(c) Extended meander line

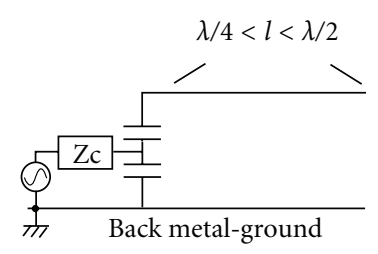

(d) Equivalent circuit

Figure 1: Small and low-profile capacitive feed meander line antenna (CFMA).

of 0.001 . The substrate dimension is fixed at $22.5 \mathrm{~mm} \times$ $14 \mathrm{~mm}\left(0.091 \lambda_{0} \times 0.057 \lambda_{0}\right)$ and satisfies the condition of electrically small antennas $(k a=0.338<0.5$ ( $k$ : wave number and $a$ : radius of a sphere surrounding the antenna) [1]. The meander line has a width $\left(W_{m}\right)$ of $1 \mathrm{~mm}$ and spaced $\left(W_{d}\right)$ at $0.5 \mathrm{~mm}$ with the adjacent lines. A metallic feed

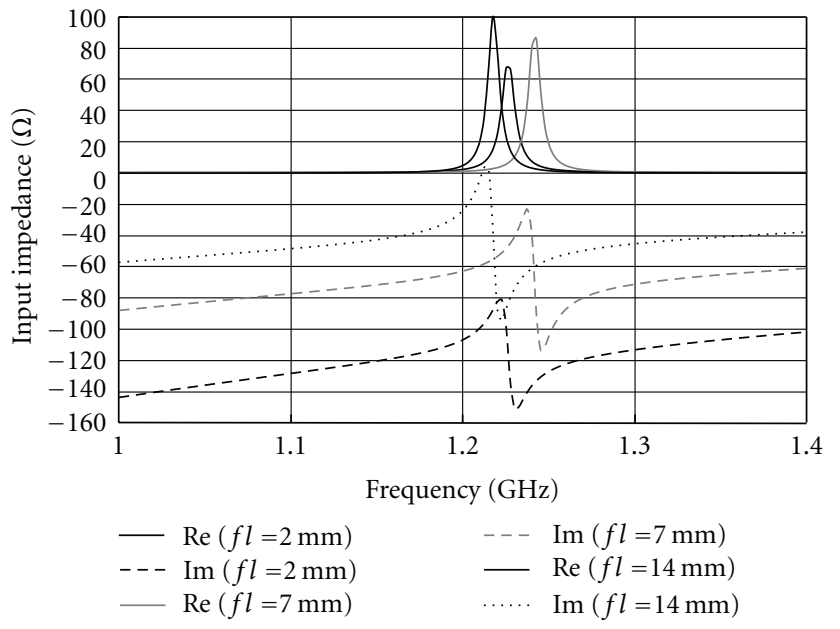

FIGURE 2: Variation in input impedance of the CFMA with $f l$

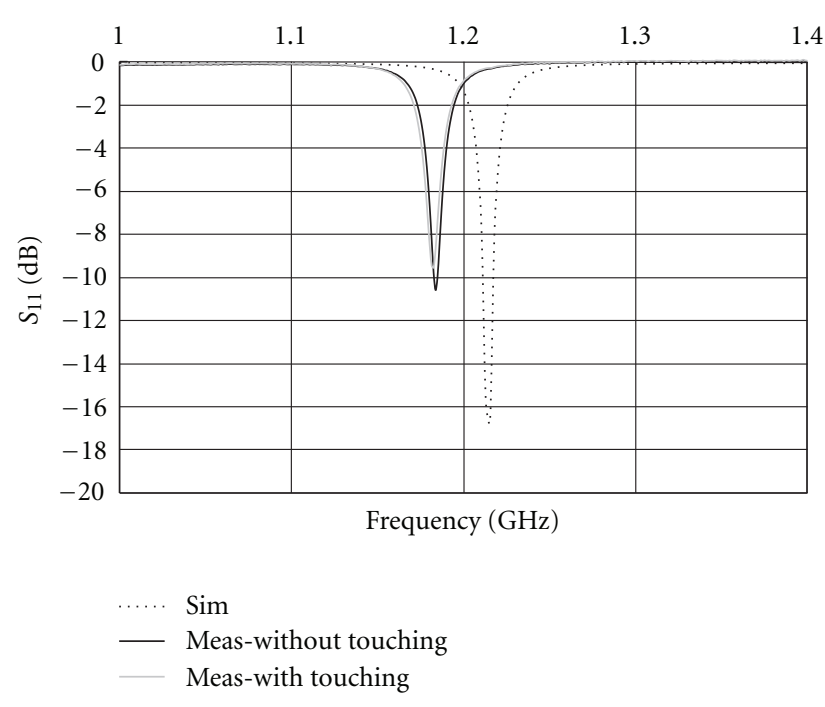

FIGURE 3: $S_{11}$ characteristics with and without touching the SMA connector connected to the CFMA.

plate is installed in between the meander line and the back conductor. The back conductor, which acts as the ground plane, is $22.5 \mathrm{~mm} \times 14 \mathrm{~mm}$. The feed plate has a length $(f l)$ of $14 \mathrm{~mm}$ and width $(f w)$ of $2 \mathrm{~mm}$. The imaginary part of the input impedance of the antenna is controlled primarily by varying the $f l$ and $f w$, substrate thicknesses Th1 and Th2, and the length of the extended meander line $(\mathrm{ml})$, as shown in Figure 1(c). The imaginary part of the input impedance can be independently controlled using these parameters as shown in Figure 2. This corresponds to the variation in capacitors in the equivalent circuit shown in Figure $1(\mathrm{~d})$. In addition, the antenna generates very small leakage current on the outer conductor surface of the connected coaxial cable. The effect of touching the SMA connector with the human hand is also investigated, and the results are shown in Figure 3. The antenna shows stable $S_{11}$ characteristics even if the SMA connector is touched with the hand. However, the antenna 

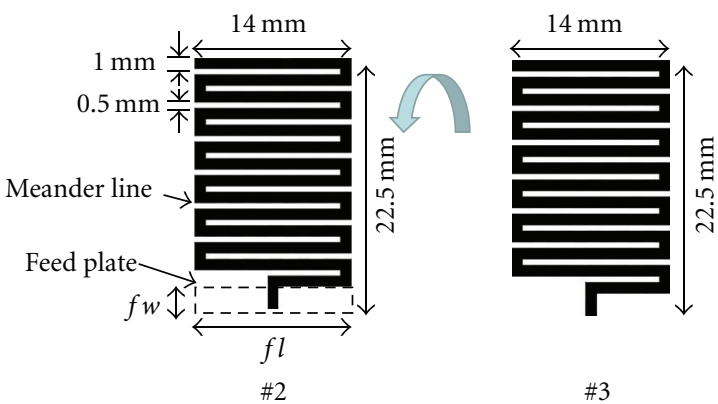

(a) CFMA stacked a meander line in the same direction (2LCFMA1)
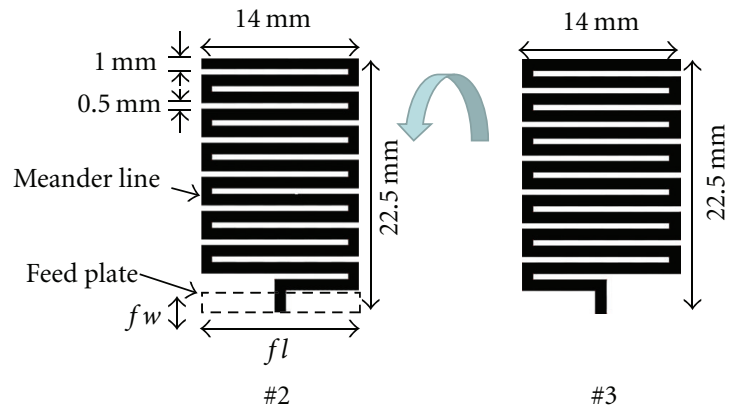

(b) CFMA stacked a meander line in the opposite direction (2LCFMA2)

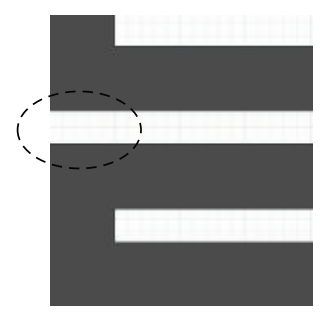

(c) Expanded figure of 2LCFMA1

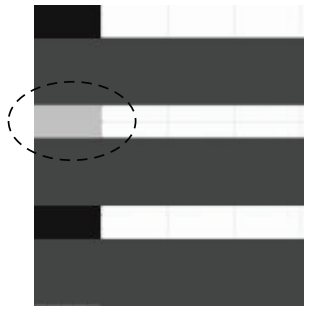

(d) Expanded figure of 2LCFMA2

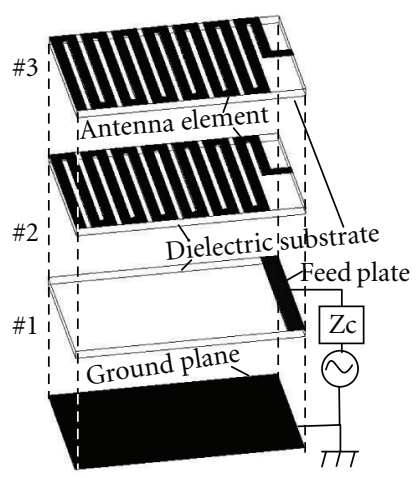

(e) Dismantled structure for 2LCFMA1

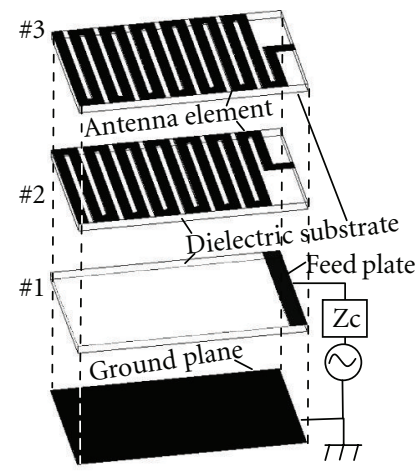

(f) Dismantled structure for 2LCFMA2

FIgURE 4: Proposed stacked structures with two layers.

shows low antenna gain of around $-10 \mathrm{dBi}$. Therefore, novel structures are presented in the next section in order to enhance the antenna gain.

\section{Enhancement of Gain}

3.1. Two-Layer Stacked Structure. A meander line is stacked on the presented CFMA to enhance the gain. So, the structure has two layers of meander lines. Two kinds of stacked structures are proposed. In Figures 4(a) and 4(c), the two meander lines of the antenna are in the same direction $(2 \mathrm{~L}$ CFMA1). But in Figures 4(b) and 4(d), the second meander line is reversed and placed on the first layer (2L-CFMA2). The 2L-CFMA2 has regions where the meander lines of the two layers are not overlapped as shown in Figure 4(d). Since an additional meander line layer is used in this stacked structure, the height of these antennas is increased by $0.8 \mathrm{~mm}$ and is shown in Figures $4(\mathrm{e})$ and $4(\mathrm{f})$.

3.2. Simulated Results. The simulated results for the input characteristics of these antennas are shown in Figure 5. In Figure 5(a), the resonance frequency is shifted to higher frequency by stacking a meander line. This shift in the frequency is due to the capacitance incorporated by the stacked meander line layer. Moreover, the resonance fre- quency of 2L-CFMA2 is shifted more to the higher frequency than the 2L-CFMA1, because of the reduced capacitance between the two meander layers due to the reduction of the overlapped metal area. Figures 5(b)-5(d) show the Smith chart expressions of the input impedance and radiation impedance for CFMA, 2L-CFMA1, and 2L-CFMA2. The radiation resistance shown here of the CFMA is lower than that of the other two structures. In Figure 5(b), the self-resonance condition is satisfied at around $1.252 \mathrm{GHz}$ (serial resonance) and $1.260 \mathrm{GHz}$ (parallel resonance) for CFMA. Similarly, this condition is satisfied at 1.502 and $1.510 \mathrm{GHz}$ for 2L-CFMA1 and 1.695 GHZ and $1.705 \mathrm{GHz}$ for 2L-CFMA2. The resonance frequencies of input impedance are different from the self-resonance frequencies. This is probably due to the skin depth of the metallic loss.

Figure 6 shows the simulated antenna gain of these antennas. The antenna characteristics at the resonance frequency are presented in Table 1 . The gain of the CFMA is enhanced by stacking the meander line. The gain of the 2L-CFMA2 has increased by around $6 \mathrm{~dB}$ as compared to the CFMA. This is due to the electric field generated at the left and right edges of the structure where the meander lines of the two layers are not overlapped as shown in Figure 7. This region behaves like slot antennas and contributes to higher gain. 


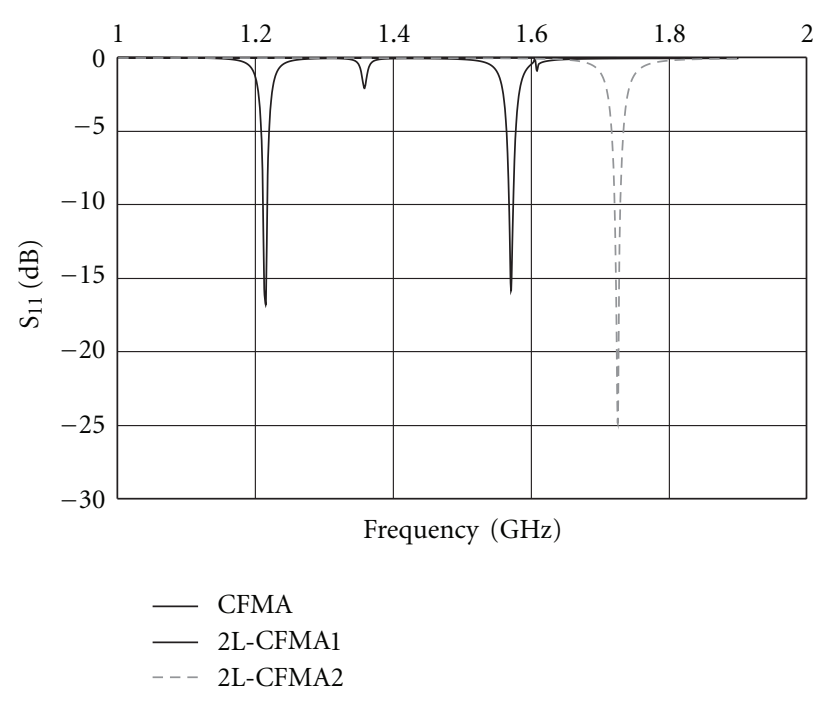

(a) $S_{11}$ characteristics

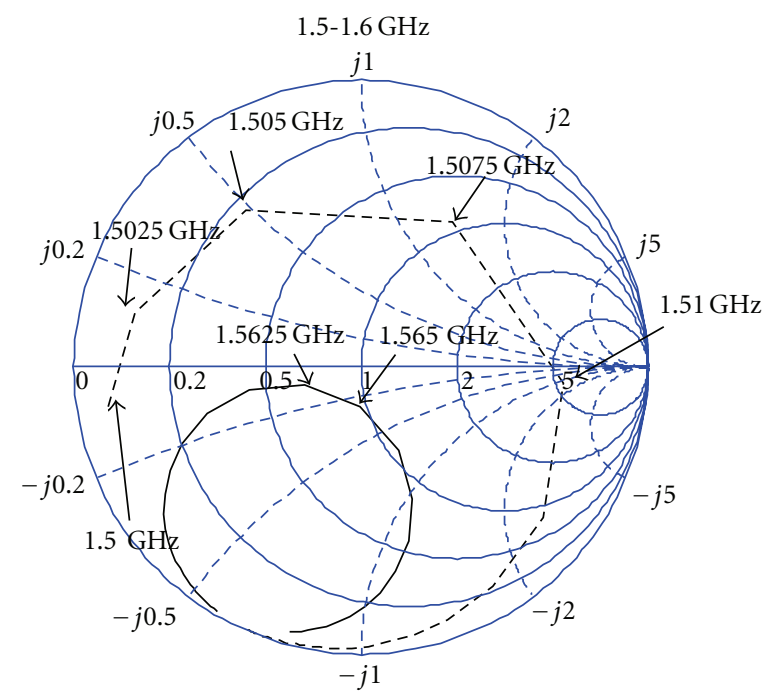

- Input impedance
-- - Radiation impedance

(c) Smith chart expression for 2L-CFMA1

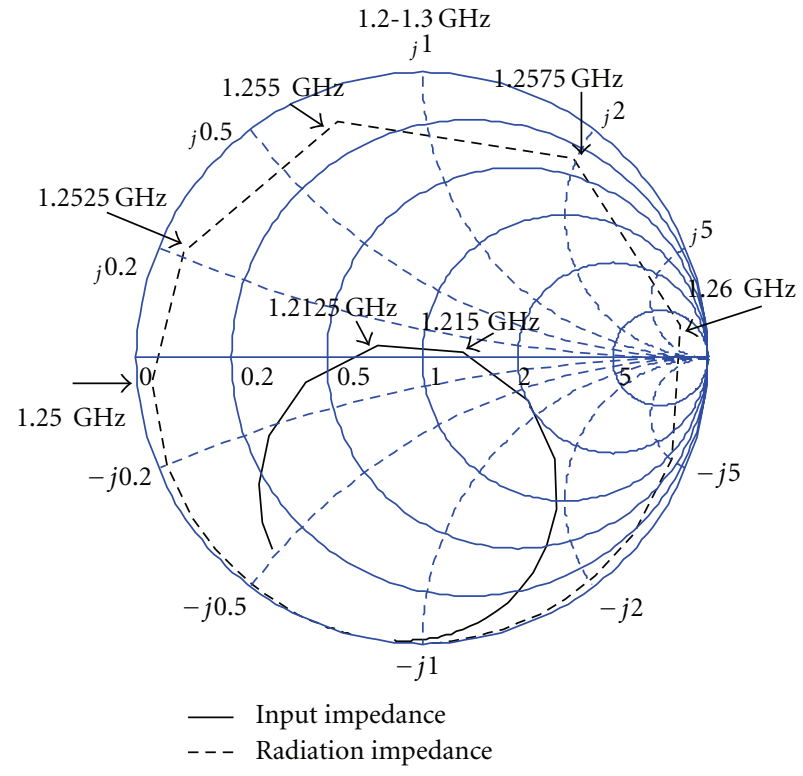

(b) Smith chart expression for CFMA

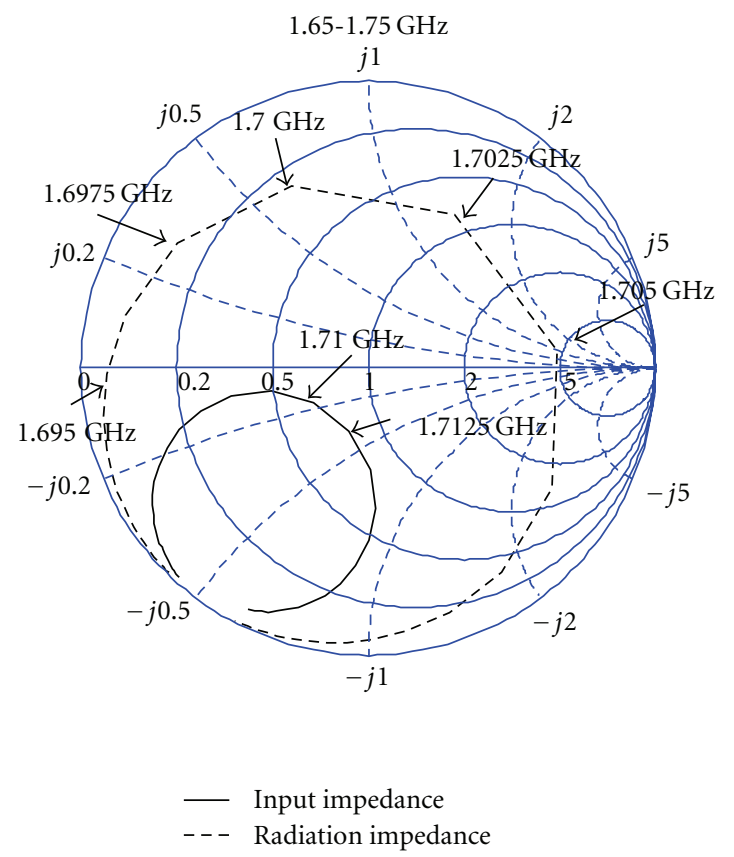

(d) Smith chart expression for 2L-CFMA2

FIGURE 5: Simulated input characteristics: (a) S11 characteristics, (b) Smith chart expression for CFMA, (c) Smith chart expression for 2L-CFMA1, and (d) Smith chart expression for 2L-CFMA2.

3.3. Three-Layer Stacked Structure. Based on the previous section, an additional meander line, which is opposite to that of the adjacent layer, is installed with the same height of the feed plate at the feed plate layer of the 2L-CFMA2 to enhance the antenna gain as shown in Figure 8. Therefore, the structure, three-layered CFMA (3L-CFMA), has three layers of meander line although the height of the antenna is the same as that of the 2L-CFMA. The simulated results of input characteristics and the antenna gain are shown in Figures 9 and 10, respectively. The resonance frequency of 3L-CFMA is shifted more to the higher frequency than the 2L-CFMA2 by installing a meander line. A small resonance occurs at around $1.55 \mathrm{GHz}$ where the antenna gain has minimum. This may be due to the capacitance between the 


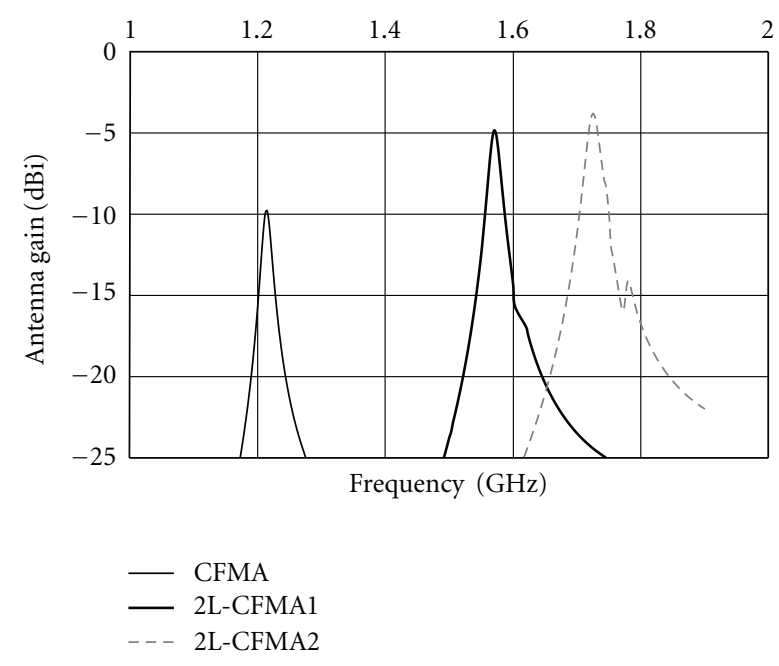

FIgURE 6: Simulated antenna gain characteristics.
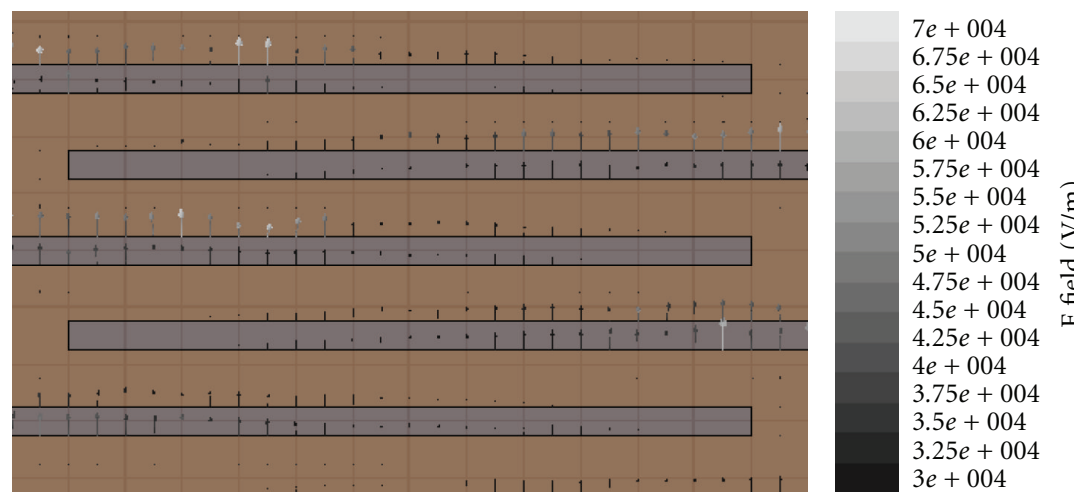

(a) 2L-CFMA1
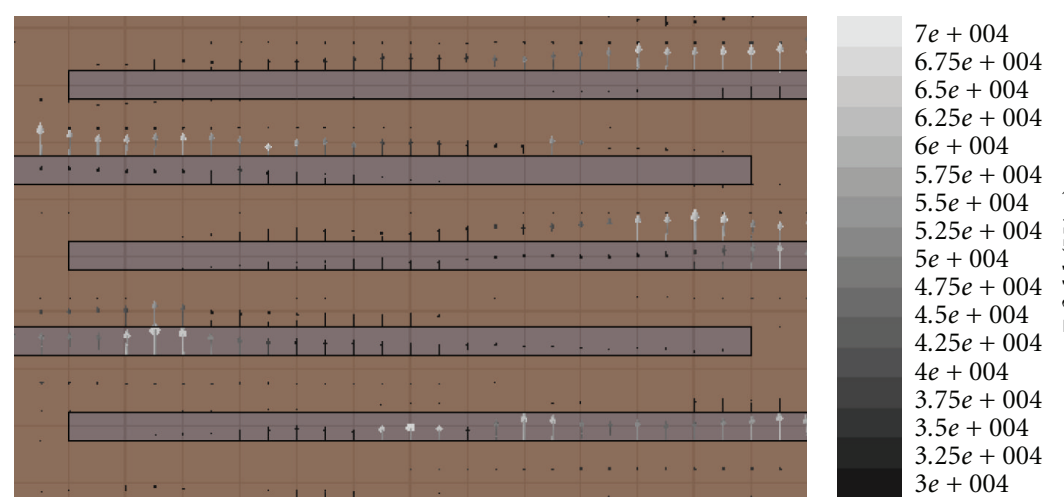

(b) 2L-CFMA1

FIgURE 7: Electric field on the meander lines

two meander lines in the same direction and the inductance offered by the two meander lines. In Figure 9(b), the Smith chart expression shows the input and radiation impedance. The radiation resistance shown here is higher than $2 \mathrm{~L}$ CFMA1 and 2. Furthermore, the self-resonance condition is satisfied at $1.727 \mathrm{GHz}$ and $1.735 \mathrm{GHz}$. These frequencies are higher than those of the other three structures and closer to the serial and parallel resonance frequencies of the input impedance. These differences show that the effect of the metallic loss is smaller than that in other structures. The gain 


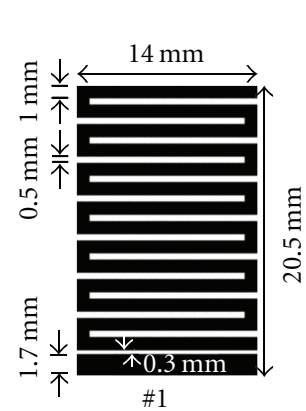

(a)

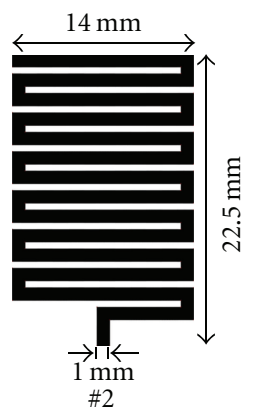

(b)

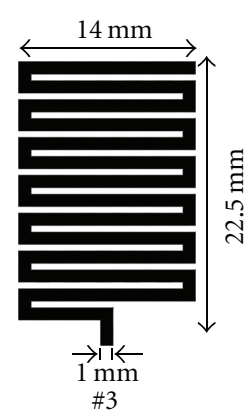

(c)

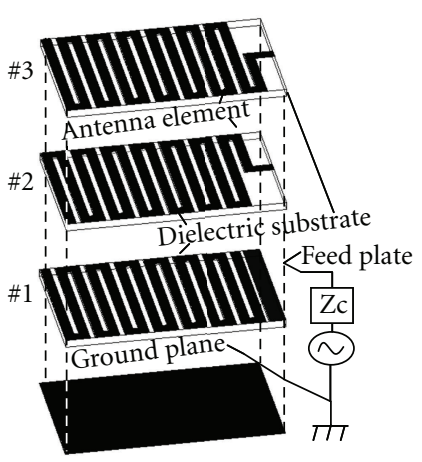

(d)

FIGURE 8: Dismantled structure of the 3L-CFMA

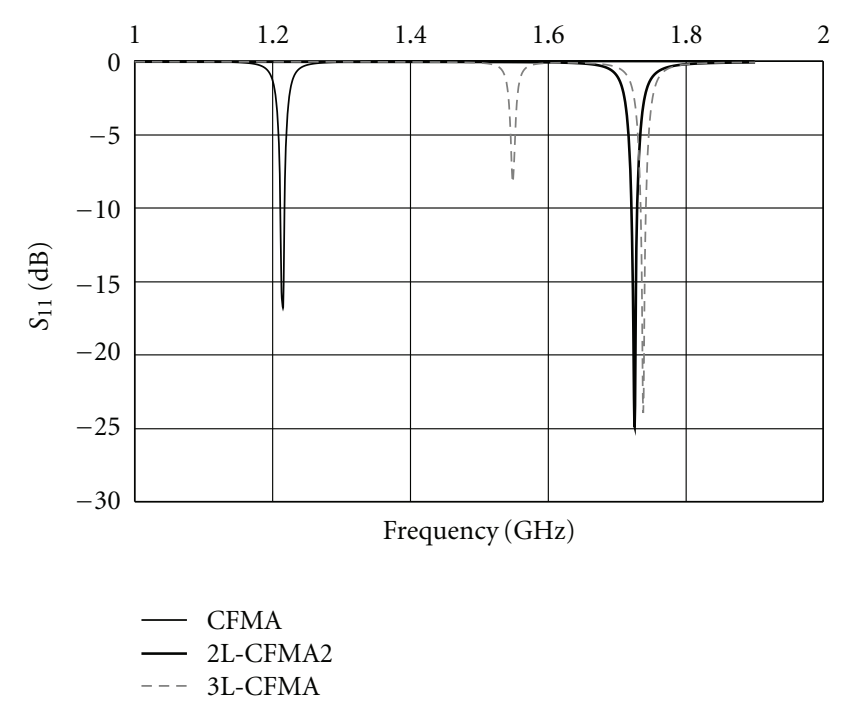

(a) $S_{11}$ characteristics

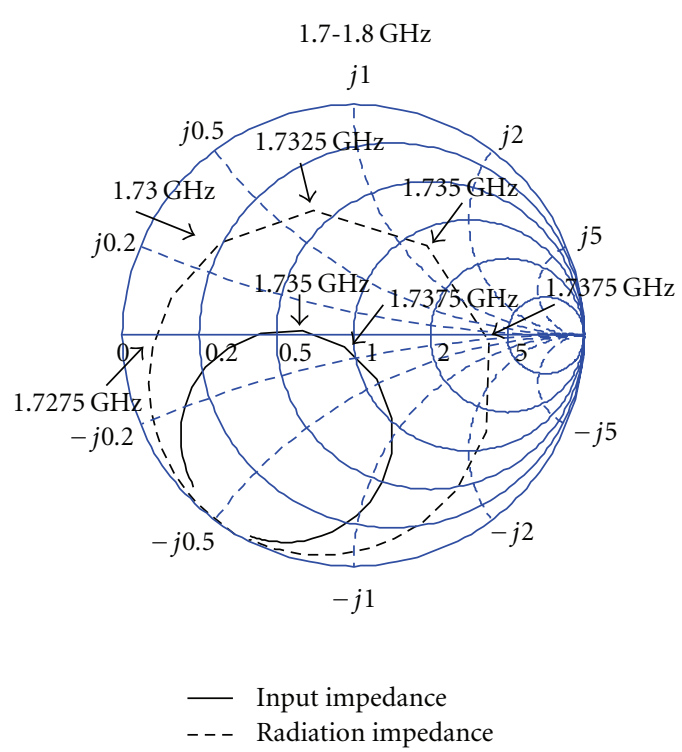

(b) Smith chart expression for 3L-CFMA

FIGURE 9: Simulated input characteristics.

TABLE 1: The antenna characteristics at the resonance frequency.

\begin{tabular}{lccl}
\hline Antenna & Resonance frequency $(\mathrm{GHz})$ & $k a$ & $\begin{array}{l}\text { Antenna gain } \\
(\mathrm{dBi})\end{array}$ \\
\hline CFMA & 1.215 & 0.338 & -9.79 \\
2L-CFMA1 & 1.57 & 0.438 & -4.84 \\
2L-CFMA2 & 1.725 & 0.481 & -3.81 \\
\hline
\end{tabular}

of the 3L-CFMA has increased by around $7 \mathrm{~dB}$ as compared to the CFMA. The antenna characteristics at the resonance frequency are presented in Table 2.

3.4. Measured Results. The 3L-CFMA $(22.5 \mathrm{~mm} \times 14 \mathrm{~mm}$ $\left(0.130 \lambda_{0} \times 0.081 \lambda_{0}\right)$ with a thickness of $2.8 \mathrm{~mm}\left(0.016 \lambda_{0}<\right.$ $\left.0.25 \lambda_{0}\right)$ and $\left.k a=0.485<0.5\right)$ is fabricated and measured.
TABLE 2: The antenna characteristics at the resonance frequency.

\begin{tabular}{lccl}
\hline Antenna & Resonance frequency $(\mathrm{GHz})$ & $k a$ & $\begin{array}{l}\text { Antenna gain } \\
(\mathrm{dBi})\end{array}$ \\
\hline CFMA & 1.215 & 0.338 & -9.79 \\
2L-CFMA2 & 1.725 & 0.481 & -3.81 \\
3L-CFMA & 1.7375 & 0.485 & -2.76 \\
\hline
\end{tabular}

Figure 11 shows the fabricated 3L-CFMA. The simulated and measured results of the $S_{11}$ characteristics of the antennas are shown in Figure 12. It could be noticed that measured resonance frequency is shifted to the lower frequency when compared to the simulated results. Figure 13 shows the radiation patterns of the antenna. The simulated maximum gain is $-2.76 \mathrm{dBi}$, and the measured gain is $-3.81 \mathrm{dBi}$. Table 3 shows 


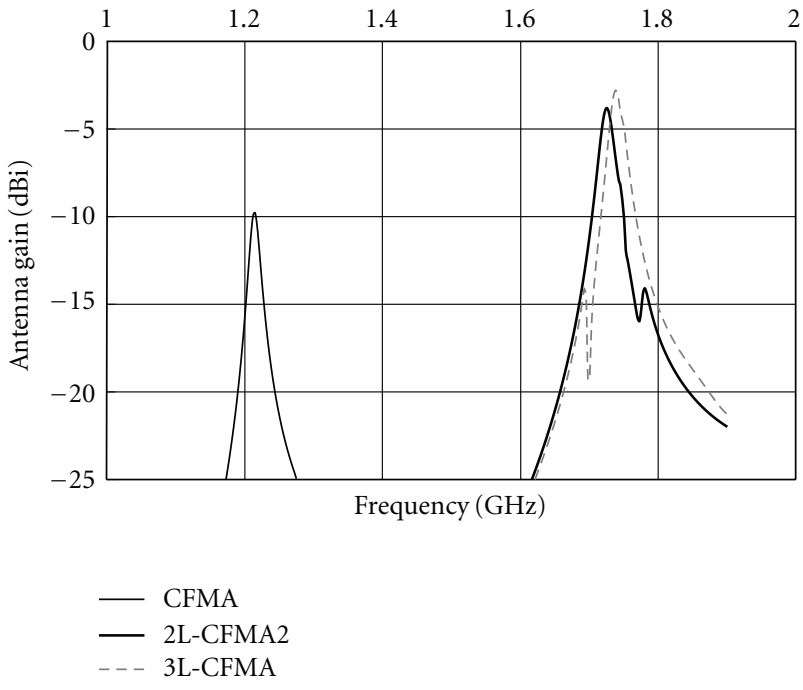

FIGURE 10: Simulated antenna gain characteristics.

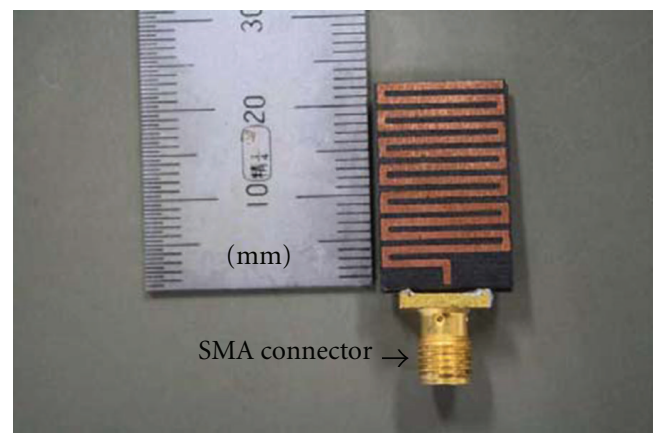

FIgUre 11: Photograph of the 3L-CFMA.

TABLE 3: The antenna characteristics at the resonance frequency.

\begin{tabular}{lcc}
\hline Antenna & Resonance frequency $(\mathrm{GHz})$ & $k a \begin{array}{l}\text { Antenna gain } \\
(\mathrm{dBi})\end{array}$ \\
\hline Sim(CFMA) & 1.215 & $0.338-9.79$ \\
Meas(CFMA) & 1.18 & $0.328-10.6$ \\
Sim(3L-CFMA) & 1.7375 & $0.485-2.76$ \\
Meas(3L-CFMA) & 1.4714 & $0.411-3.81$ \\
\hline
\end{tabular}

the simulated and measured antennas characteristics at the resonance frequency. The differences between simulated and measured results are due to fabrication error and slight leakage current. Also, the adhesive used to stack the meander line layers greatly influences the performance of the antenna because the electric field is concentrated at this region. This causes the shift in the resonance frequency and the reduction in the antenna gain. The 3L-CFMA can enhance the gain by around $7 \mathrm{~dB}$ as compared to the CFMA in measurement. Although the antenna has the same radiation pattern as a dipole antenna, the front-back ratio can be improved by using larger back conductor.

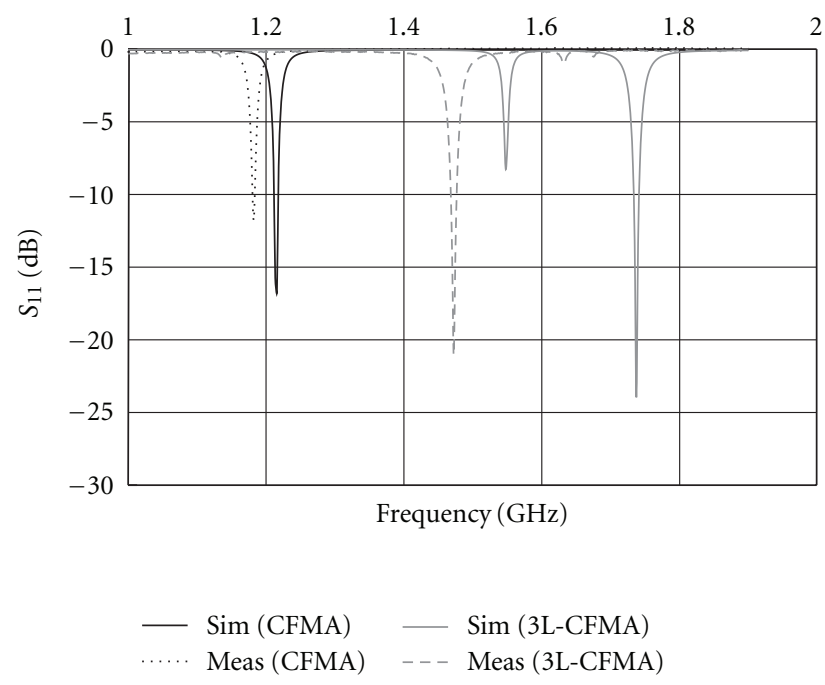

FIGURE 12: Simulated and measured $S_{11}$ characteristics.

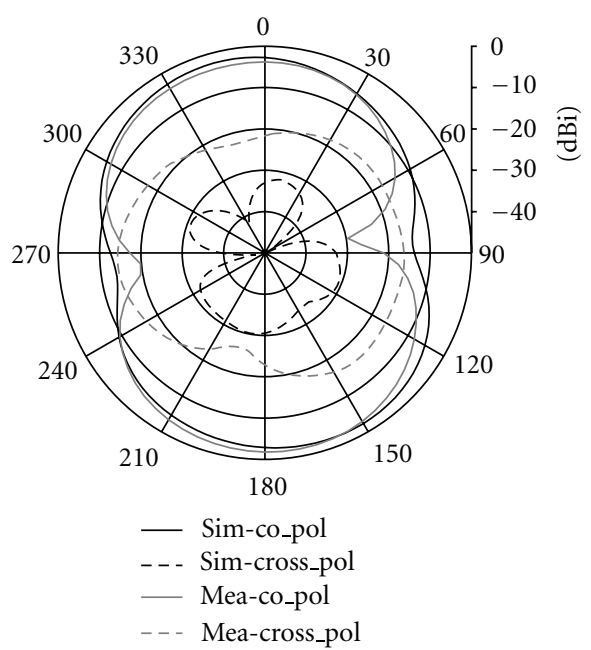

(a) $y z$-plane

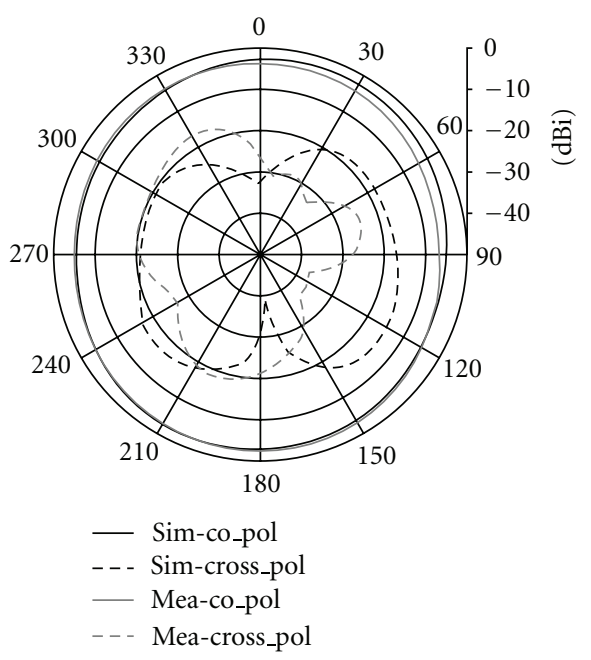

(b) $x z$-plane

Figure 13: Radiation patterns of the 3L-CFMA. 


\section{Conclusion}

The techniques to enhance the gain of a low-profile, electrically small meander antenna using a capacitive feed structure with stacked layers have been presented. The antenna gain of $-9.8 \mathrm{dBi}$ in the CFMA structure can be enhanced by a twolayered stacked meander line antenna with opposite meander lines (2L-CFMA2). The gain of 2L-CFMA2 has increased to $-3.81 \mathrm{dBi}$. Finally, a three-layered meander line antenna (3L-CFMA), which has the same height as that of the $2 \mathrm{~L}-$ CFMA, could achieve a gain of $-2.76 \mathrm{dBi}$, which is around $7 \mathrm{~dB}$ higher as compared to the CFMA. These antennas can find their application in RFIDs and mobile terminals.

\section{Acknowledgments}

The authors would like to acknowledge the Japan Science and Technology Agency (JST) for its financial support with the Collaborative Development of Innovative Seeds Program. They would also thank Mr. Kazuki Iwata, Technologist of Kumamoto University, for his technical supports.

\section{References}

[1] S. R. Best, "A discussion on the properties of electrically small self-resonant wire antennas," IEEE Antennas and Propagation Magazine, vol. 46, no. 6, pp. 9-22, 2004.

[2] A. Erentok and R. W. Ziolkowski, "Metamaterial-inspired efficient electrically small antennas," IEEE Transactions on Antennas and Propagation, vol. 56, no. 3, pp. 691-707, 2008.

[3] K. V. S. Rao, P. V. Nikitin, and S. F. Lam, "Antenna design for UHF RFID tags: a review and a practical application," IEEE Transactions on Antennas and Propagation, vol. 53, no. 12, pp. 3870-3876, 2005.

[4] T. Tsukiji and Y. Kumon, "Modified transmission line type antennas for mobile communication," IEICE Transactions on Communications, vol. E75-B, no. 8, pp. 775-780, 1992.

[5] A. Thumvichit, T. Takano, and Y. Kamata, "Ultra low profile dipole antenna with a simplified feeding structure and a parasitic element," IEICE Transactions on Communications, vol. E89-B, no. 2, pp. 576-579, 2006.

[6] A. Thumvichit, T. Takano, and Y. Kamata, "Impedance matching of a half-wavelength dipole in proximity to a PEC plane," in Proceedings of the IEICE General Conference, March 2004, B-1-129.

[7] S. R. Best, "A comparison of the resonant properties of small space-filling fractal antennas," IEEE Antennas and Wireless Propagation Letters, vol. 2, pp. 197-200, 2003.

[8] W. Choi, S. Kwon, and B. Lee, "Ceramic chip antenna using meander conductor lines," Electronics Letters, vol. 37, no. 15, pp. 933-934, 2001.

[9] A. Galehdar, D. V. Thiel, S. G. O'Keefe, and S. P. Kingsley, "Efficiency variations in electrically small, meander line RFID antennas," in Proceedings of the IEEE Antennas and Propagation Society International Symposium (AP-S '07), pp. 2273-2276, June 2007.

[10] G. A. E. Vandenbosch and A. R. Van de Capelle, "Study of the capacitively fed microstrip antenna element," IEEE Transactions on Antennas and Propagation, vol. 42, no. 12, pp. 1648-1652, 1994.
[11] C. R. Rowell and R. D. Murch, "A capacitively loaded PIFA for compact mobile telephone handsets," IEEE Transactions on Antennas and Propagation, vol. 45, no. 5, pp. 837-842, 1997.

[12] T. Terada, K. Ide, K. Iwata, and T. Fukusako, "Design of a small, low-profile print antenna using a Peano line," Microwave and Optical Technology Letters, vol. 51, no. 8, pp. 1833-1838, 2009.

[13] S.-I. Sekine and H. Shoki, "Characteristics of T-type monopole antenna with parallel resonance mode," Electronics and Communications in Japan, Part I: Communications, vol. 87, no. 2, pp. 28-36, 2004 (Japanese).

[14] C. Icheln, J. Krogerus, and P. Vainikainen, "Use of balun chokes in small-antenna radiation measurements," IEEE Transactions on Instrumentation and Measurement, vol. 53, no. 2, pp. 498-506, 2004.

[15] J. C.-E. Sten, A. Hujanen, and P. K. Koivisto, "Quality factor of an electrically small antenna radiating close to a conducting plane," IEEE Transactions on Antennas \& Propagation, vol. 49, no. 5, pp. 829-837, 2001.

[16] S.-L. Chen and K.-H. Lin, "A folded dipole with a closed loop antenna for RFID applications," in Proceedings of the IEEE Antennas and Propagation Society International Symposium (AP-S '07), pp. 2281-2284, June 2007.

[17] K. Ide, "A small and low profile meander antenna using capacitive feed structure," in Proceedings of the International Symposium on Antennas and Propagation (ISAP '09), pp. 353356, Bangkok, Thailand, October 2009. 

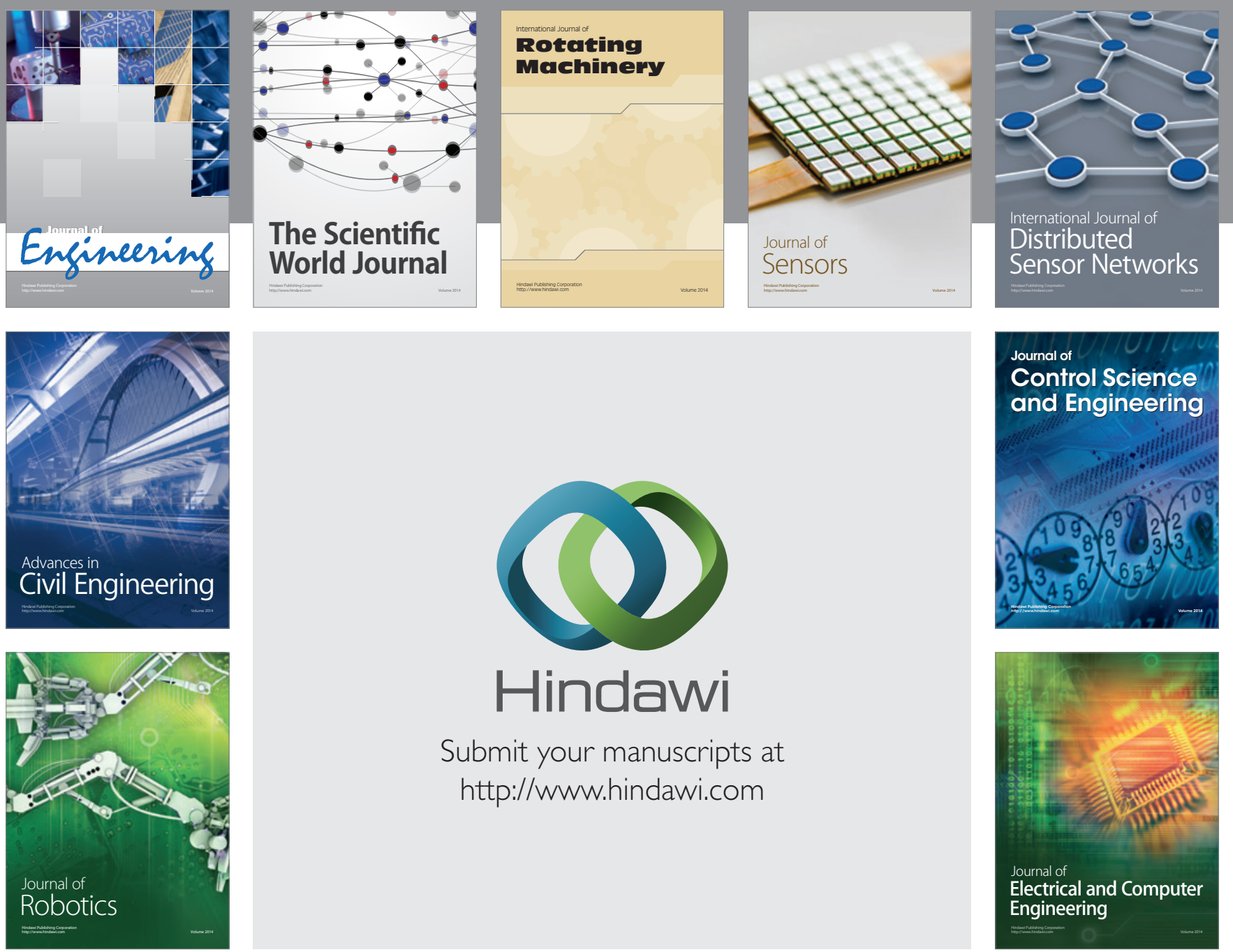

Submit your manuscripts at

http://www.hindawi.com
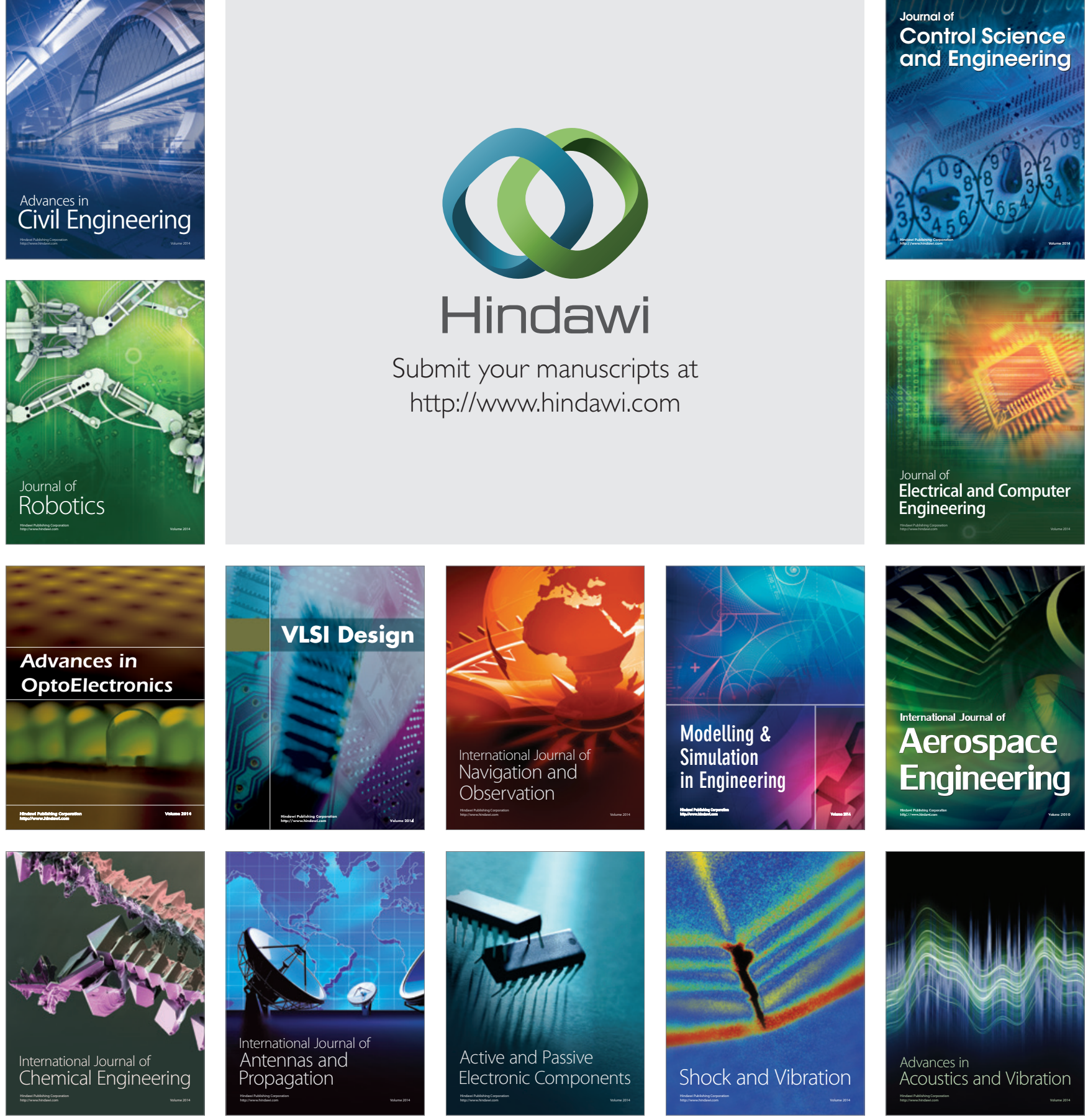